\title{
LA AMBIVALENCIA ANTE LA CIENCIA Y LA TECNOLOGÍA
}

\author{
THE AMBIVALENCE TOWARD SCIENCE \\ AND TECHNOLOGY
}

\author{
CRISTÓBAL TORRES ALBERO \\ Universidad Autónoma de Madrid
}

\begin{tabular}{ll}
\hline PALABRAS CLAVE ADICIONALES & ADDITIONAL KEYWORDS \\
Cultura científica y tecnológica, Percepción & Public Understanding of Science and \\
social de la ciencia y la tecnología, Opinión & $\begin{array}{c}\text { Technology, Social Perception of Science and } \\
\text { pública. }\end{array}$ \\
Technology, Public Opinion.
\end{tabular}

RESUMEN. Este artículo sostiene la tesis de la ambivalencia como eje básico en la conformación de las representaciones sociales de la ciencia y la tecnología, ambivalencia que descansa en la naturaleza dual de la actividad tecnocientífica y que, por tanto, está presente desde su irrupción histórica como variable capaz de afectar el decurso de las sociedades. Pero esta ambivalencia ha aumentado y se ha hecho más visible en tanto que las sociedades avanzadas contemporáneas, como sociedades de conocimiento, pivotan su estructura sobre el vector tecnocientífico. El artículo presenta evidencia empírica diversa, de fuentes secundarias y primarias, y de índole cualitativa y cuantitativa, que avala esta interpretación.

ABSTRACT. This article maintains the ambivalence thesis as an essential part to constitute the social representations of science and technology. The ambivalence is based on the dual nature of technoscientific activity. Therefore, it has been present since its historical irruption as a variable capable of shaping over the society. This ambivalence has grown and made more visible while the contemporary advanced societies, as knowledge societies, are based on the technoscientific vector. The article presents several empirical evidence, from primaries and secondaries sources, and quantitative and qualitative nature, to support this interpretation.

E-mail: cristobal.torres@uam.es

Revista Internacional de Sociología (RIS)

Tercera Época, $\mathrm{N}^{\circ}$ 42, Septiembre-Diciembre, 2005, pp. 9-38 
RIS

REVISTA INTERNACIONAL DE SOCIOLOCÍA

№ 42, SEPTIEMBRE-DICIEMBRE, 2005

CRISTÓBAL TORRES ALBERO

\section{INTRODUCCIÓN}

La ciencia y la tecnología, intrínsecamente vinculadas y sin solución de continuidad en las sociedades avanzadas contemporáneas, desempeñan un papel central por su importancia en las formas de estructuración social, cultural y política, por su decisivo impacto en la articulación de la actividad económica, así como por representar una forma de conocimiento y una posibilidad de actuar sobre la naturaleza, de alta sofisticación y complejidad. Por ello, y desde un enfoque macro, la tecnociencia ha conformado un referente crucial en la configuración de las instituciones típicas de las sociedades modernas. $\mathrm{Y}$ de la misma manera, desde el ámbito micro, ha fijado los valores y el sentido que en buena medida orientan nuestras acciones sociales 1 .

A ambos planos, macro y micro, se referían los clásicos de la sociología con expresiones tales como el destacado papel del crecimiento de las fuerzas productivas capitalistas para propiciar el cambio histórico (Marx), el aumento de la sofisticación del conocimiento conforme crece la complejidad de la sociedad (Durkheim) o la progresiva racionalización y el desencantamiento del mundo como rasgos definitorios de las sociedades modernas (Weber). En efecto, con Weber podemos afirmar que frente a los principios de la tradición o el carisma, que daban lugar a formas de pensar y actuar basadas en la costumbre o en principios sobrenaturales, la ciencia y la tecnología, a partir de su moderna irrupción con la llamada Revolución Científica (siglos XVI-XVII), se han aupado a una posición central y hegemónica en la estructura de las sociedades modernas.

Dada esta base, no es extraño que las ideas sobre la ciencia y la tecnología hayan estado habitualmente dominadas por una consideración meliorativa de las mismas, a la que podemos etiquetar como concepción Ilustrada. En este sentido, la primera consideración que emergió de la ciencia arranca precisamente con la señalada Revolución Científica. La primera línea se vincula a la visión baconiana de la ciencia como fuente de abundancia. Con su obra La Gran Restauración (1620), Francis Bacon proclamó su deseo de progreso a partir de la aplicación de la nueva ciencia, y señaló la necesidad de dotarla con una serie de recursos materiales y humanos que permitiesen a la casa de la sabiduría, la Casa de Salomón - el antecedente de la Royal Society-, generar los conocimientos y aplicaciones para la mejora de la vida y el incremento del conocimiento. De esta manera, la máxima baconiana de que el conocimiento es poder expresa la confianza en que la ciencia permita al pueblo la posibilidad de producir todas las cosas buenas

\footnotetext{
${ }^{1}$ Este artículo forma parte del proyecto de investigación Cultura cientifica y tecnológica (BSO2001-0171/CPSO), financiado por el Ministerio de Ciencia y Tecnología. Agradezco a Miguel Beltrán, Pedro González Blasco y Rubén Blanco su ayuda y comentarios críticos.
} 
que comporta el beneficio común; y que la ciencia, al desvelar y aplicar el conocimiento inscrito en la naturaleza, puede transformar las condiciones de la vida humana y propagar el imperio del hombre sobre el universo. En esta línea hay que recordar que Bacon no sólo fue un destacado filósofo, sino que también era un influyente político de su tiempo, y su originalidad radica en la centralidad que concedió a las aplicaciones prácticas y a cómo la ciencia podía organizarse socialmente y convertirse en un instrumento que permitiese la generación de las novedades técnicas que asegurasen una mejora de la vida.

La idea, también sugerida por Bacon, de que el progreso de la civilización está directamente vinculado a la centralidad de la ciencia y la tecnología en nuestra cultura constituye el segundo eje de la imagen positiva de la tecnociencia. Esta noción alcanzó una poderosa fuerza intelectual con su apogeo durante el positivismo decimonónico, encabezado por Saint-Simon y Comte entre otros, que entendía la ciencia y la tecnología como la base de la acumulación y el progreso material e intelectual. De ahí arranca la noción de progreso como vector de un proceso universal de mejora material y moral, que tiene su mejor expresión en la tesis de Comte de la ley de los tres estados de desarrollo de la humanidad, en la que el positivo o científico representa la culminación del avance de la humanidad gracias a la razón y a la técnica, ejemplificadas en la emergente sociedad industrial. La idea de que la ciencia y su expresión práctica, la tecnología, constituyen una actividad indudablemente acumulativa y progresiva constituirá el referente de la práctica totalidad de la filosofía moral y científica durante el siglo XIX y buena parte del XX, y su influencia en el marco cultural e intelectual todavía alcanza nuestros días.

Finalmente, el tercer y más actual eje que constituye la imagen ilustrada de la tecnociencia es la idea, expresada entre otros por Nagel, de la neutralidad valorativa de orientación tecnocrática; es decir, la idea de que la tecnociencia es un procedimiento neutral que resuelve problemas concretos, selecciona medios para lograr fines dados, y distingue entre hechos y valores. Esta racionalidad instrumental permite que la tecnociencia se conforme como un valor en sí mismo, lo que ha llevado a algunas corrientes a considerar que sólo aquello que puede resolverse bajo esta lógica tiene sentido en el debate político y social. Por ello, los científicos y tecnólogos se constituyen en expertos que no sólo resuelven problemas concretos, sino que también informan a las instituciones y a la opinión pública acerca del elenco de escenarios posibles, y sobre las soluciones óptimas para el progreso de la humanidad.

Estas ideas de la ciencia y la tecnología como sinónimos de bienestar y progreso moral y técnico pueden etiquetarse como una concepción ilustrada o positiva de la tecnociencia, que ha dominado hegemónicamente las ideas políticas, sociales y culturales de nuestras sociedades occidentales hasta, por lo menos, la contestación crítica que frente a la tecnociencia comenzó a emerger en torno a los años sesenta del siglo pasado. Con ello, han constituido la triada de ideas, valores e 
RIS

REVISTA INTERNACIONAL DE SOCIOLOGÍA

№ 42, SEPTIEMBRE-DICIEMBRE, 2005

CRISTÓBAL TORRES ALBERO

imágenes sociales que, de manera más o menos explícita, ha asumido la primera oleada de estudios e investigaciones empíricas del llamado (en Europa) campo de la "comprensión pública de la ciencia", o de su variante (en Estados Unidos) de la "alfabetización científica" (Pardo, 2001).

Frente a esta tesis ilustrada o meliorativa, en este artículo se defiende la tesis de la ambivalencia como eje consustancial en la conformación de las representaciones sociales de la ciencia y la tecnología. Ambivalencia que, desde la irrupción histórica de la tecnociencia como variable capaz de afectar el decurso de las sociedades, está presente en el imaginario social, pero que se ha incrementado y hecho más visible en tanto que las actuales sociedades avanzadas occidentales pivotan su estructura social, económica, cultural e incluso política sobre el vector tecnocientífico.

Con el concepto de ambivalencia existe un problema para un enfoque sociológico en tanto que su uso ha sido básicamente psicológico, refiriéndose a cómo las personas orientan, al mismo tiempo y en direcciones psicológicamente opuestas, los afectos, las ideas y las acciones de los individuos de una sociedad concreta. Pero aquí no nos interesa la cuestión de la ambivalencia en el plano de la personalidad, sino el análisis de cómo se articulan en direcciones opuestas tales afectos, ideas y acciones. Por eso abordamos, tal y como reclama Merton en su conocido ensayo Ambivalencia sociológica (1980), la cuestión de la ambivalencia en la dinámica de una estructura social determinada. El objetivo es, de un lado, establecer cuál es la fuente dual que establece y alimenta la ambivalencia $y$, de otro, identificar cómo ésta llega a incrustarse en la estructura de las relaciones sociales de un tipo de sociedad dado, es decir, dar cuenta de los procesos sociales por los que queda incorporada a un contexto social. Así, aun cuando la ambivalencia puede estar latente debido a la propia configuración y posibilidades del objeto que la genera, la manifestación de ésta frente a la univalencia depende de las condiciones de la estructura social que acoge al objeto en cuestión. Por ello esta dimensión social de la ambivalencia es una de las fuentes más importantes que genera la ambivalencia psicológica.

En el resto del artículo aportaré, en primer lugar, evidencia empírica de distinta índole, de fuentes secundarias y primarias, de orientación cualitativa y cuantitativa, que apoya la tesis de la ambivalencia. Luego bosquejaré la fuente de dicha ambivalencia que, a mi entender, descansa en la naturaleza dual de la actividad tecnocientífica y que, por tanto, está presente desde la irrupción histórica de estas fuerzas. Finalmente, apuntaré los procesos que han permitido una notoria activación de la ambivalencia en las sociedades avanzadas contemporáneas al hilo del crucial papel que desempeña la tecnociencia en la estructuración y evolución de nuestras sociedades de ciencia, o de la información y del conocimiento. 


\section{EVIDENCIA EMPÍRICA DE FUENTES SECUNDARIAS}

En un reciente artículo (Torres, 2005) he mostrado, mediante el recurso al análisis longitudinal de distintas encuestas realizadas en España, cómo en los últimos veinte años se ha producido un significativo descenso en las actitudes meliorativas ante la ciencia y la tecnología consideradas en términos generales, de tal manera que en la actualidad sólo la mitad de la ciudadanía opta por una consideración positiva de las mismas. La otra mitad se divide entre quienes muestran un punto de vista negativo (los menos), y aquellos que mantienen una posición equidistante o ambivalente en la consideración de pros y contras de la tecnociencia (que alcanza a una tercera parte del total de la opinión pública según las dos últimas encuestas de la FECYT) o bien de indiferencia o desconocimiento.

Una aproximación empírica complementaria a la consideración general que merece la tecnociencia en la opinión pública puede realizarse sobre aspectos concretos de sus repercusiones en la sociedad. Para el caso español, en el Banco de Datos del CIS se dispone de una serie de encuestas que pueden usarse para indagar en la cuestión que nos ocupa.

Una primera serie viene referida por cinco encuestas realizadas en julio y diciembre de 1991, diciembre de 1992, diciembre de 1993 y febrero de 1995, en las que se preguntaba por las ventajas o desventajas que el progreso científico y tecnológico aportaría a cuatro cuestiones planteadas: el desarrollo económico, la calidad de vida en la sociedad, la seguridad y protección de la vida humana y la conservación del medio ambiente y la naturaleza. Se cuenta con la ventaja de que las preguntas fueron idénticas en su redacción en todos los casos.

Los resultados de la Tabla 1 muestran una estructura actitudinal dual de la mayor parte de la opinión pública, de tal manera que mientras el impacto de la tecnociencia en los dos primeros aspectos (desarrollo económico y calidad de vida) son valorados meliorativamente por más de las dos terceras partes de la ciudadanía, en el aspecto de la seguridad de la vida humana las opiniones positivas y negativas están equilibradas (salvo en la última encuesta), y son mayoritariamente negativas en lo que respecta a la conservación del medio ambiente. En esta misma línea, Atienza y Luján (1997) han mostrado, a partir de los datos de un estudio del CIS de abril-mayo de 1996, cómo en torno a la mitad de la ciudadanía española estima que en alguna medida la biotecnología y la ingeniería genética entrañan riesgos.

A partir de estos datos podría ya aventurarse la existencia de una representación social bifronte de la tecnociencia, dado que una mayoría significativa considera como positivo el impacto que la ciencia y la tecnología tienen en el desarrollo económico o en la calidad de vida (la traslación práctica de los conceptos ilustrados de abundancia y progreso), mientras que la evaluación es negativa en lo referido a las consecuencias que la tecnociencia tiene para la conservación del medio ambiente $\mathrm{y}$, en menor medida, en la seguridad y protección de la vida humana (la plasmación de la pesadilla que planteó la novela de Mary Shelley, Frankenstein). 


\section{RIS}

REVISTA INTERNaCIONAL DE SOCIOLOGÍA

Tabla 1.

Pregunta: ¿Piensa Ud. que el progreso científico y tecnológico aporta más bien ventajas o más bien desventajas para.......?

\begin{tabular}{|l|c|c|c|c|c|}
\hline Cuestiones y Respuestas & $\begin{array}{c}\text { Julio } \\
1.991 \\
\text { (n: } 2.513)\end{array}$ & $\begin{array}{c}\text { Diciembre } \\
1991 \\
\text { (n: } 4.257)\end{array}$ & $\begin{array}{c}\text { Diciembre } \\
1992 \\
\text { (n: } 4.277)\end{array}$ & $\begin{array}{c}\text { Diciembre } \\
1993 \\
\text { (n: } 2.500)\end{array}$ & $\begin{array}{c}\text { Febrero } \\
1995 \\
\text { (n: } 2.500)\end{array}$ \\
\hline $\begin{array}{l}\text { El Desarrollo Económico: } \\
\text { - Más bien ventajas } \\
\text { - Más bien desventajas }\end{array}$ & $78,9 \%$ & $70,3 \%$ & $66,0 \%$ & $65,6 \%$ & $69,8 \%$ \\
$12,7 \%$ & $12,6 \%$ & $16,1 \%$ & $17,6 \%$ & $15,7 \%$ \\
\hline La Calidad de Vida en la & & & & & \\
Sociedad: & & & & & \\
- Más bien ventajas & $77,3 \%$ & $72,9 \%$ & $72,6 \%$ & $72,2 \%$ & $68,4 \%$ \\
- Más bien desventajas & $15,0 \%$ & $11,9 \%$ & $14,3 \%$ & $15,3 \%$ & $16,7 \%$ \\
\hline La Seguridady Protección & & & & & \\
de la Vida Humana: & & & & & \\
- Más bien ventajas & $45,1 \%$ & $45,5 \%$ & $44,9 \%$ & $46,3 \%$ & $69,7 \%$ \\
- Más bien desventajas & $44,1 \%$ & $32,3 \%$ & $37,4 \%$ & $34,6 \%$ & $16,1 \%$ \\
\hline La Conservación del & & & & & \\
Medio Ambiente y la & & & & & \\
Naturaleza: & & & & & \\
- Más bien ventajas & $19,3 \%$ & $24,9 \%$ & $21,5 \%$ & $24,8 \%$ & $34,7 \%$ \\
- Más bien desventajas & $72,5 \%$ & $58,8 \%$ & $65,0 \%$ & $60,7 \%$ & $52,5 \%$ \\
\hline
\end{tabular}

Fuente: Banco de Datos del CIS. Elaboración propia.

Esta idea de las representaciones sociales duales de la tecnociencia al considerar los resultados concretos de su aplicaciones, también puede dar sentido a los datos de una encuesta de CIRES realizada en 1992 en la que se indagaba a cerca de la relación de una serie de valores con las, entonces emergentes, nuevas tecnologías de la información y las comunicaciones. Tal como muestra la Tabla 2, tanto los valores meliorativos como los negativos fueron vinculados a las nuevas tecnologías por la mayoría de los encuestados. Dadas las altas frecuencias registradas, se deduce que buena parte de los entrevistados tuvieron que señalar que las nuevas tecnologías se asocian a la vez con el progreso, la comodidad, la eficacia, el conocimiento, la riqueza y las oportunidades y, sin solución de continuidad, con el paro, la deshumanización, la amenaza, la desigualdad y el poder. Con los datos de esta misma encuesta, Díaz de Rada, Ayerdi y Olazarán (1998) han mostrado las notables diferencias existentes en las actitudes de la opinión pública española cuando se comparan las actitudes (favorables) ante el desarrollo científico y tecnológico en general con la percepción (negativa) de los efectos concretos de las nuevas tecnologías y su impacto laboral, social, etc. 
Tabla 2.

Relación de valores con las Nuevas Tecnologias (\%)

\begin{tabular}{lccc}
\hline VALORES & SI & NO & N.S./N.C. \\
\hline Progreso & 91,8 & 4,3 & 3,9 \\
Paro & 75,8 & 20,2 & 4,0 \\
Deshumanización & 65,3 & 25,5 & 9,2 \\
Comodidad & 90,9 & 5,4 & 3,7 \\
Eficacia & 84,1 & 9,8 & 6,1 \\
Conocimiento & 84,0 & 9,6 & 6,4 \\
Amenaza & 57,0 & 30,7 & 12,3 \\
Desigualdad & 60,5 & 28,8 & 10,7 \\
Riqueza & 76,5 & 16,8 & 6,7 \\
Oportunidades & 64,1 & 26,7 & 9,2 \\
Poder & 77,2 & 15,3 & 7,5 \\
\hline
\end{tabular}

Fuente: González Blasco (1992: 249).

En tercer lugar, más allá de la consideración metodológica de los efectos que la redacción de la pregunta pudiera tener en los resultados de la encuesta, los datos presentados en la Tabla 3 también pueden interpretarse en esta misma dirección de las representaciones sociales duales de la tecnociencia. En efecto, resulta llamativa la muy distinta consideración que merecen la ciencia y la tecnología a la opinión pública española cuando se plantean en una misma encuesta las consecuencias que su desarrollo provocará en un futuro a largo plazo (veinte años). Así, al indagar a cerca del grado de beneficio, las opiniones afirmativas (muy o bastante beneficioso) alcanzan, con la excepción de marzo de 1997, a casi el 70\% de los entrevistados. Por el contrario, cuando se pregunta por el grado de riesgo las opiniones afirmativas (mucho o bastante riesgo) también las suscriben en torno al $60 \%$ de los encuestados. Este dato es incluso mayor, debido al impacto de la llamada crisis de las "vacas locas", en la encuesta de marzo de 1997.

La tesis que aquí se sostiene sobre la ambivalencia hacia la tecnociencia, ha sido esbozada en la monografía de Miller, Pardo y Niwa (1998), en la que se comparan cuatro importantes estudios realizados mediante encuesta en la 
R I S

Unión Europea, Estados Unidos, Japón y Canadá entre 1989 y 1995. Aun cuando los autores, que articularon su investigación en la línea de la tesis clásica o ilustrada, entienden que los datos registrados en dichos estudios apoyan la existencia de una mayor y más relevante imagen positiva de la ciencia y la tecnología, también dan cuenta de la existencia en la opinión pública de las sociedades avanzadas de una apreciable reserva frente a las actividades tecnocientíficas y sus consecuencias. Tras someter sus datos a un análisis factorial confirmatorio, afirman que en Europa y Japón existía la misma probabilidad de que las personas que obtuvieran una puntuación alta en una dimensión de evaluación de la tecnociencia (p.e. positiva) alcanzaran una puntuación alta o baja en la otra dimensión (p.e. negativa). Por ello, y puesto que podría haberse esperado una correlación negativa mayor, dado el contenido sustantivo de los elementos que conformaban las dos dimensiones, los autores estiman que "este grado de independencia sugiere que muchos adultos europeos reconocían el potencial positivo de la ciencia y la tecnología y, por otra parte, expresaban las preocupaciones personales por las repercusiones negativas potenciales de la ciencia y la tecnología en sus valores tradicionales y religiosos". En este sentido, y en la misma línea aquí defendida, los tres autores concluyen su estudio comparativo internacional destacando que "dos esquemas distintos -el de la confianza en la promesa de la ciencia y de la tecnología, y el de las reservas acerca del impacto de la ciencia y la tecnología - operan de forma simultánea en las mentes de la mayoría de los individuos de las sociedades industriales modernas, si bien lo hacen a veces con distintas fuerzas y en diferentes combinaciones según el grupo social e incluso el país de que se trate. Algunas cuestiones pueden activar uno de los esquemas, en tanto que otras cuestiones activarán el otro esquema" (Miller, Pardo y Niwa, 1998: 102 y 124). Afirmaciones concretas que en este artículo se asumen por completo, dado que apuntan en la dirección interpretativa que aquí se trata de profundizar.

Pero ahondar en esta tesis de la ambivalencia, y avalarla o falsarla empíricamente, implica la necesidad de recurrir a una estrategia metodológica alternativa al método cuantitativo de la encuesta, al que han reducido sus estrategias de recogida de datos los tradicionales estudios sobre "percepción social de la ciencia y la tecnología", e incluso los más recientes de la "comprensión pública de la ciencia". Encuestas que, por otra parte, han estado, implícita o explícitamente, orientadas por los supuestos de la tesis ilustrada: evaluación del grado de apoyo a la tecnociencia, grado del interés que despiertan frente a otras actividades, relación entre conocimiento y apoyo, etc. (Torres, 2005). Esta conjunción de la tesis ilustrada con la técnica de la encuesta ha impedido que se profundice en el alcance de las representaciones sociales ambivalentes de la tecnociencia en las sociedades contemporáneas. 
Tabla 3.

Valoración de la ciencia y la tecnología en términos de su beneficio y riesgo

\begin{tabular}{|c|c|c|c|}
\hline Respuestas/Años & $\begin{array}{c}\text { Abril-Mayo 1.996 } \\
\text { (n: 2.552) }\end{array}$ & $\begin{array}{c}\text { Marzo 1.997 } \\
\text { (n: 2.497) }\end{array}$ & $\begin{array}{c}\text { Marzo-Abril 2.001 } \\
\text { (n: 2.492) }\end{array}$ \\
\hline (A) BENEFICIO & & & \\
Afirmativas & $69,2 \%$ & $52,0 \%$ & $69,5 \%$ \\
Negativas & $18,0 \%$ & $26,6 \%$ & $17,7 \%$ \\
N.S./N.C. & $12,9 \%$ & $21,4 \%$ & $12,6 \%$ \\
\hline (B) RIESGO & & & \\
Afirmativas & $57,2 \%$ & $70,1 \%$ & $61,1 \%$ \\
Negativas & $28,3 \%$ & $14,2 \%$ & $26,8 \%$ \\
N.S./N.C. & $14,5 \%$ & $15,7 \%$ & $12,0 \%$ \\
\hline
\end{tabular}

Fuente: Banco de Datos del CIS. Elaboración propia.

- Las dos preguntas de los tres estudios son las siguientes: (A) "En general, ¿cree usted que en los próximos veinte años el desarrollo de la ciencia y la tecnología será muy beneficioso, bastante, poco o nada beneficioso para nuestro mundo?". Y, (B) “En general, ¿cree usted que en los próximos veinte años el desarrollo de la ciencia y la tecnología traerá consigo muchos riesgos, bastantes, pocos o ningún riesgo para nuestro mundo?".

- El estudio de Abril-Mayo de 1996 es el número 2.213 (preguntas 4 y 5). Ámbito nacional de municipios de más de 10.000 habitantes, si bien con muestra específica en las áreas metropolitanas de Barcelona, Bilbao, Madrid, Sevilla y Valencia donde se incluyen algunas poblaciones que tienen menos de 10.000 habitantes". Población de 18 a 64 años. Encuesta monográfica "Actitudes ante los avances cientificos y tecnológicos".

- El estudio de Marzo de 1997 es el número 2.242 (preguntas 11 y 12). Ámbito nacional, 18 y más años.

- El estudio de Marzo de 2001 es el número 2.412 (preguntas 2 y 3). Ámbito nacional, 18 y más años. Encuesta monográfica "Opiniones y actitudes de los españoles hacia la biotecnologia".

\section{EVIDENCIA EMPÍRICA CUALITATIVA}

El principal problema de las encuestas, acogidas a la llamada metodología cuantitativa que se destaca por su representatividad estadística, es que hacen descansar la identificación de las variables y supuestos que estructuran o conforman el fenómeno estudiado, en el marco teórico que, de manera más o menos elaborada, maneja el investigador. Así, las encuestas son especialmente útiles cuando se trata de cuantificar variables, precisar su distinto nivel de impacto, comparar diversos grupos o identificar los cambios a través del tiempo. Pero son insuficientes cuando se trata de llevar a cabo una indagación más profunda en la configuración contextual del fenómeno, dado que imponen una rejilla (el cuestionario con la formulación de preguntas y posibilidades restringidas de respuestas) sobre el mundo 
RIS

REVISTA INTERNACIONAL DE SOCIOLOGIA

№ 42, SEPTIEMBRE-DICIEMBRE, 2005

CRISTÓBAL TORRES ALBERO

social, que detecta automáticamente algunos aspectos pero que, a cambio, pasa por alto otros. Con ello se pierde buena parte de la heterogeneidad y pluralidad que nutre la realidad social.

Para paliar este déficit, y en sintonía con la idea del pluralismo metodológico que asumo, recurrí al enfoque cualitativo para abrir las "redes" y tratar de identificar la posible existencia de otras dimensiones o variables que estructuren el curso del problema que nos ocupa. En este sentido, sostengo que el uso de las técnicas cualitativas, complementarias del recurso a la encuesta, permite ofrecer ventajas metodológicas en la indagación del fundamento y dinámica de la tesis de la ambivalencia que aquí se defiende.

Por ello, en el curso del proyecto de investigación reseñado, procedí a realizar una serie de reuniones de grupo según el siguiente diseño. En primer lugar, se eligieron cuatro variables sociodemográficas que, en función de los estudios empíricos realizados anteriormente y de la literatura existente, se consideraron como puntos de partida para aprehender la representatividad estructural y establecer la homogeneidad del grupo de discusión: estudios, ideología, edad y ocupación. De cara a operacionalizar las variables y concretar el diseño de las reuniones de grupo, cada una de estas cuatro variables se dicotomizaron siguiendo los criterios que se indican a continuación, siempre con el fin de homogeneizar el grupo y facilitar la generación de un discurso estructurado y con riqueza argumental.

Estudios:

1. Personas sin estudios o con estudios básicos.

2. Personas con estudios medios o superiores.

Ideología:

3. Personas de ideología conservadora (centro-derecha).

4. Personas de ideología progresista (centro-izquierda).

Edad:

5. Personas de entre 18 y 29 años.

6. Personas de 30 y más años.

Ocupación:

7. Personas con trabajos manuales, administrativos o comerciales.

8. Personas con trabajos profesionales o técnicos superiores.

De esta manera, se realizaró un total de ocho reuniones de grupo, aun cuando a partir del quinto grupo comenzó a registrarse una repetición de argumentos y discursos en torno a la pregunta inicial formulada en términos generales ("su opinión sobre la ciencia y la tecnología"). No obstante, procedimos a completar los ocho grupos inicialmente previstos, si bien, y de acuerdo con el principio metodológico 
cualitativo de la saturación informativa - equivalente al de la representatividad estadística en las encuestas-, no realizamos ningún grupo adicional, dado que dicha saturación indicaba que no iba a generarse nueva evidencia empírica que redundase en la mejora de la significatividad aprehendida.

Los resultados obtenidos del análisis de los discursos de las distintas reuniones de grupo mantenidas corroboran la tesis de que existe una vía estructurada de representar a la ciencia y la tecnología bajo el marco de los distintos tipos afectivos, intelectuales y conativos de la ambivalencia, y que dicha veta no sólo aparece en todos los grupos de discusión, sino que, además, surge también como contrapunto entre quienes optan por una interpretación decididamente meliorativa o peyorativa.

No obstante, hay que hacer constar que esta ambivalencia no impide que el fiel de la balanza se incline hacia el lado positivo en tanto que se considera que la tecnociencia es una fuerza poderosa que aporta "cosas deslumbrantes" (en la medicina, en las tecnologías de la información y las comunicaciones, etc.) o "proyecta luz a las sombras" (la razón frente a la ignorancia). En ese sentido, se considera que la tecnociencia es una de las fuentes, tal vez la principal, de la abundancia, la máxima expresión del progreso en su dimensión material o económica de nuestras sociedades, amén de las positivas repercusiones sociales y culturales que genera ("tiempo libre", "libertad", "mayor calidad de vida", "pone fin a la ignorancia", etc.).

Pero sin solución de continuidad, también se construyen discursos críticos que argumentan que muchos valores morales están afectados negativamente por los resultados de la tecnociencia. Sus consecuencias no sólo alteran de manera constante las formas de concebir las relaciones sociales, sino que incluso amenazan directamente al ciclo de la naturaleza. Así, se llega a afirmar que es capaz de crear "efectos amenazadores para la sociedad, pues, dominada por los intereses del capital, puede alterar, y ya lo está haciendo, lo natural". En este lado se identifica explícitamente todo lo relativo a la energía nuclear (que lleva aparejado el "pecado original" de Hiroshima y Nagasaki), y la más reciente capacidad de manipulación genética al hilo del desarrollo alcanzado por la biotecnología. En este sentido, aunque la tecnociencia no sea responsable directa de algunas de sus peores consecuencias, como la bomba atómica, su capacidad técnica las ha hecho posible.

Estos dos tipos de discurso son conocidos y se vinculan tanto a la concepción ilustrada de la tecnociencia, como al discurso crítico que explícitamente emergió desde la segunda mitad del siglo XX, y al que más adelante me refiero. Sin embargo, la novedad radica en la confirmación de la hipótesis aquí sustentada sobre la existencia de una tercera posición de ambivalencia que emerge ante los resultados y consecuencias de la tecnociencia. Esta ambivalencia va aunando los puntos positivos y los perfiles negativos de la misma, y permite construir un discurso estructurado que vincula a la mayor parte de los participantes en los distintos grupos de discusión mantenidos. 
En esta concepción ambivalente la cuestión que aparece en los distintos grupos es hacía dónde nos lleva el vertiginoso ritmo de innovación tecnocientífica. Se usa la expresión de que la tecnociencia es "un caballo desbocado al que es muy difícil parar". Situación que, además, se agrava por la ausencia de un mínimo control sobre esta actividad, debido, en buena medida, a la configuración de científicos y tecnólogos como un grupo minoritario y elitista, cada vez más alejado de la más amplia sociedad y, en el peor de los casos, tentado de vincularse a grupos poderosos ajenos al bienestar del conjunto de la sociedad.

En definitiva, esta ambivalencia hacia la tecnociencia se perfila en los actores sociales sobre el supuesto tácito de un mecanismo de evaluación permanente que emitirá un juicio positivo en tanto que espera obtener continuos beneficios de dicha actividad. Pero que, a la vez, también está alerta sobre las posibilidades de encontrar perjuicios en casos concretos, o de prever potenciales y graves peligros.

También hay que reseñar que esta ambivalencia no presenta una asociación fuerte con ninguna de las variables sociodemográficas contempladas en el diseño de los grupos de discusión. Es decir, aparece tanto en jóvenes como en adultos y mayores, entre universitarios o personas con estudios básicos o sin estudios, de ideología progresista o conservadora. Sin embargo, es reseñable que las distintas representaciones sociales (sean positivas, negativas o ambivalentes) tienden a tomar un perfil más nítido y preciso entre las personas con mejor nivel educativo o con unas orientaciones ideológicas más sólidas.

En suma, en los discursos de las reuniones de grupo se registra una corriente destacada, que se aglutina con parecida intensidad en los distintos segmentos sociales, que entiende y representa a la tecnociencia como una fuerza bifronte, en la que la cara positiva aparece con mayor fuerza que el lado negativo, pero en el que la tendencia hacia la evaluación pragmática y la ambivalencia afectiva, argumental y conativa se configura, especialmente en el nivel latente, con una relevante potencia en los discursos de los distintos actores sociales considerados.

\section{EVIDENCIA EMPÍRICA CUANTITATIVA}

Para evaluar el alcance de la tesis de la ambivalencia, afinar en los aspectos cuantitativos de su presencia en las representaciones sociales ante la tecnociencia, buscar la significatividad de sus vínculos con las variables sociodemográficas y, en definitiva, someterla al test que supone estimar su grado de representatividad estadística, introduje una serie de preguntas vinculadas con la cuestión de la representación social y la cuestión de la ambivalencia en una encuesta diseñada para atender el más amplio enfoque de la cultura científica en el ámbito de la Comunidad de Madrid, y sobre el universo de sus ciudadanos de 18 y más. 
Esta encuesta, cuyo trabajo de campo se llevó a cabo en el mes de diciembre de 2000 por la empresa Demoscopia, se realizó a partir de un diseño muestral polietápico estratificado con arreglo a las tres siguientes variables sociodemográficas: género, edad y niveles de hábitat. En total se realizaron 800 entrevistas, en 24 municipios y 80 secciones censales, repartidas proporcionalmente según los distintos pesos demográficos de las variables y segmentos identificados. En la fijación de las cuotas muestrales, y con el fin de robustecer la representatividad estadística del diseño muestral, se cruzaron las variables de género y edad con la del tipo de hábitat, y se tomaron criterios aleatorios en la elección de las secciones censales, calles, y viviendas particulares.

El total de entrevistas realizadas implica un margen de error estadístico máximo para los datos globales obtenidos del $\pm 3,5 \%$, asumiendo el supuesto más desfavorable $(\mathrm{P}=\mathrm{Q}=0,5)$ en la varianza o heterogeneidad poblacional, y con un nivel de confianza de 2 sigmas, es decir, con el 95,5\% de probabilidades de que la estimación de los datos muestrales obtenidos se ajuste a la realidad del conjunto del universo definido.

La cuestión de la ambivalencia se abordó en varias preguntas, de las que aquí quisiera destacar dos. Una primera, orientada más a indagar en el nivel concreto y latente de las representaciones sociales y, otra, encuadrada en términos generales y en su dinámica manifiesta. La redacción de ambas y sus opciones de posibles respuestas se presentan a continuación:

- Dígame su grado de acuerdo con cada una de las siguientes frases que le voy a leer, usando la mencionada escala del 1 al 5 , donde el 1 significa que usted está totalmente en desacuerdo con la frase y el 5 que está totalmente de acuerdo. Por supuesto, puede utilizar cualquier puntuación intermedia. Si usted no tiene una opinión formada en alguna de las frases, no tenga inconveniente en decirlo así. (ENTREVISTADOR: ROTAR Y LEER):

FRASE 1: La ciencia es la máxima expresión de prosperidad en nuestra sociedad. FRASE 2: La ciencia sirve, sobre todo, para resolver problemas.

FRASE 3: La ciencia resuelve problemas pero también los crea.

FRASE 4: La ciencia es fuente de pesadillas para nuestra sociedad.

- Si tuviera usted que hacer balance de los aspectos positivos y negativos de la ciencia, ¿cuál de las siguientes opciones que le presento en la siguiente tarjeta reflejaría mejor su opinión? (ENTREVISTADOR, ENSEÑAR TARJETA Y LEER PAUSADAMENTE):

OPCIÓN 1: Teniendo en cuenta todos los aspectos, los beneficios de la ciencia son mayores que sus perjuicios.

OPCIÓN 2: Teniendo en cuenta todos los aspectos, los perjuicios de la ciencia son mayores que los beneficios. 
OPCIÓN 3: Teniendo en cuenta todos los aspectos, los beneficios y perjuicios de la ciencia están equilibrados.

OPCIÓN 4: No tengo una opinión formada sobre este aspecto.

OPCIÓN 5: No contesta.

Con la primera pregunta se buscó una herramienta más fina y neutra con la que registrar la ambivalencia concretada en los tres ejes básicos que enmarcan la actividad tecnocientífica: la prosperidad, la resolución de los problemas y la amenaza de sus resultados. Sobre esta base, y para equilibrar las afirmaciones de uno y otro signo sometidas a evaluación, se establecieron cuatro afirmaciones al desdoblar el eje de "resolver los problemas" en dos dimensiones ("sobre todo resolver problemas", y "resolver problemas pero también crearlos").

La segunda pregunta también mantuvo el sentido de presentar un equilibro en su diseño, si bien en este caso se optó por forzar la disyuntiva de un posicionamiento único y generalista, más allá de perfilar los niveles concretos en los que se expresa la ambivalencia. Hay que reseñar que por razones ajenas a la dirección técnica del estudio, en ambas preguntas la mención explícita en el cuestionario fue sólo a la ciencia y no a la tecnología, o al apócope de la tecnociencia.

Las puntuaciones medias obtenidas en la primera pregunta, que se presentan en la Tabla 4, permiten sostener la hipótesis de que existe una considerable ambivalencia en la representación social de la ciencia, y que ésta puede alcanzar una considerable presencia, al menos en el ámbito concreto de la evaluación de sus resultados. Así, de las cuatro frases construidas la que registra la puntuación media más alta es la tercera $(4,33)$, esto es, aquella que afirma que la ciencia resuelve problemas pero también los crea (negativa), seguida de la segunda frase que destaca la dimensión (positiva) instrumental de la ciencia $(3,80)$. Es decir, las dos afirmaciones que perfilan los márgenes de la ambivalencia frente a los extremos de los polos meliorativo y adverso. Además, la referida tercera frase es la que registra la menor desviación típica $(0,91)$, o lo que es lo mismo, presenta una distribución más homogénea del total de puntuaciones recibidas; mientras que las desviaciones típicas más altas corresponden a las frases totalmente positivas o negativas (primera y cuarta). Esta cuarta afirmación es la que presenta un menor grado de acuerdo $(2,78)$.

De otro lado, si llevamos a cabo una comparación entre las dos dimensiones (positiva y negativa) consideradas, mediante una suma de medias de las dos parejas de frases, resulta que la media conjunta de ambas dimensiones es muy similar $(7,33$ y 7,11$)$. De lo que resulta que la diferencia de medias entre las dos dimensiones es de sólo 0,22 , en un rango teórico entre +8 y-8, que asume que el 0 representa el punto de ambivalencia máxima. Finalmente, tal y como puede apreciarse en la señalada tabla, la distribución de las puntuaciones medias respecto a la variable "nivel educativo" no permite sostener que exista entre los distintos segmentos sociales que genera esta variable una desigual estructura 
Tabla 4

Representación social de la ciencia según nivel de estudios en la Comunidad de Madrid

\begin{tabular}{|c|c|c|c|c|c|c|}
\hline \multirow[b]{2}{*}{ AFIRMACIONES } & \multirow{2}{*}{\begin{tabular}{|c|} 
MEDIAS \\
TOTALES \\
(Rango 1-5)
\end{tabular}} & \multirow[b]{2}{*}{$\begin{array}{c}\text { Desviación } \\
\text { Típica }\end{array}$} & \multicolumn{4}{|c|}{ MEDIAS SEGÚN ESTUDIOS } \\
\hline & & & $\begin{array}{l}\text { Sin Estudios o } \\
\text { Incompletos }\end{array}$ & Básicos & Medios & Universitarios \\
\hline $\begin{array}{l}\text { La ciencia es la } \\
\text { máxima } \\
\text { expresión de } \\
\text { prosperidad en } \\
\text { nuestra sociedad. }\end{array}$ & 3,53 & 1,28 & 3,76 & 3,58 & 3,55 & 3,39 \\
\hline $\begin{array}{l}\text { La ciencia sirve, } \\
\text { sobre todo, para } \\
\text { resolver } \\
\text { problemas. }\end{array}$ & 3,80 & 1,18 & 4,11 & 3,77 & 3,78 & 3,84 \\
\hline $\begin{array}{l}\text { Sumario } \\
\text { Afirmaciones } \\
\text { Positivas (Rango } \\
\text { entre } 10 \text { y 2) }\end{array}$ & 7,33 & - & 7,87 & 7,35 & 7,33 & 7,23 \\
\hline $\begin{array}{l}\text { La ciencia } \\
\text { resuelve } \\
\text { problemas pero } \\
\text { también los crea. }\end{array}$ & 4,33 & 0,91 & 4,48 & 4,40 & 4,35 & 4,16 \\
\hline $\begin{array}{l}\text { La ciencia es } \\
\text { fuente de } \\
\text { pesadillas para } \\
\text { nuestra sociedad. }\end{array}$ & 2,78 & 1,44 & 3,47 & 2,91 & 2,67 & 2,58 \\
\hline $\begin{array}{l}\text { Sumatorio } \\
\text { Afirmaciones } \\
\text { Negativas (Rango } \\
\text { entre } 10 \text { y 2) }\end{array}$ & 7,11 & - & 7,95 & 7,31 & 7,02 & 6,74 \\
\hline $\begin{array}{l}\text { Diferencia Total } \\
\text { (Rango entre }+8 \\
\text { y -8) }\end{array}$ & 0,22 & - & $-0,08$ & 0,04 & 0,31 & 0,49 \\
\hline
\end{tabular}

Fuente: Elaboración propia sobre datos de la encuesta sobre cultura científica de la Comunidad de Madrid (2000). 


\section{RIS}

en la representación social que nos ocupa. Y de la misma manera, tampoco se encontraron diferencias estadísticamente significativas en el resto de variables sociodemográficas controladas (nivel de alfabetización científica, ideología, edad, género, etc.).

Para dar más robustez al análisis, y dado que las puntuaciones medias no están aparentemente muy alejadas, se realizó un test " $t$ " de medias (Tabla 5) para muestras relacionadas. Se trataba de comprobar si las diferencias en la puntuación de las cuatro frases son estadísticamente diferentes ${ }^{2}$. Puesto que todas las diferencias de medias computadas son estadísticamente distintas de cero, cabe afirmar que las puntuaciones medias obtenidas para cada pregunta pueden valorarse como diferentes entre sí, lo que nos permite extraer conclusiones a partir de la misma.

Tabla 5.

Prueba " $t$ " de diferencia en medias para muestras relacionadas.

\begin{tabular}{|c|c|c|c|c|c|c|c|c|}
\hline & \multicolumn{2}{|c|}{ Frase 1 } & \multicolumn{2}{c|}{ Frase 2 } & \multicolumn{2}{c|}{ Frase 3 } & \multicolumn{2}{c|}{ Frase 4 } \\
\hline Frase 1 & - & - & $-0,265$ & 0,049 & $-0,806$ & 0,062 & 0,745 & 0,074 \\
& - & - & $-5,376$ & 0,000 & $-12,96$ & 0,000 & 10,14 & 0,000 \\
\hline Frase 2 & - & - & - & - & $-0,527$ & 0,054 & 1,029 & 0,073 \\
& - & - & - & - & $-9,749$ & 0,000 & 14,09 & 0,000 \\
\hline Frase 3 & - & - & - & - & - & - & 1,575 & 0,055 \\
& - & - & - & - & - & - & 28,82 & 0,000 \\
\hline
\end{tabular}

Sobre esta base, resulta interesante conocer las correlaciones que existen en las respuestas a cada una de las cuatro alternativas presentadas en la encuesta. En principio pudiera esperarse que si la muestra fuera polarizada, positiva o negativa, y no ambivalente, presentaría claras correlaciones teóricas negativas entre los extremos del rango de opinión (entre las respuestas a la primera frase y la cuarta afirmación) y, a la vez, correlaciones positivas entre las opciones más próximas de la escala de opinión (de un lado, entre las respuestas a la primera y segunda frase; $y$, de otro, entre las puntuaciones en la tercera y cuarta frase).

\footnotetext{
${ }^{2}$ El procedimiento prueba " $t$ " para muestras relacionadas compara las medias de dos variables de un solo grupo calculando las diferencias entre los valores de las dos variables de cada caso y contrastando si las diferencias de medias difiere de 0 . Para cada pareja de variables se ofrecen cuatro datos: (1) diferencia promedio entre las medias, (2) error medio en la diferencia, (3) prueba t de intervalo de confianza para la diferencia entre las medias; y (4) nivel de confianza asociado a la aceptación de la hipótesis nula de igualdad de medias. Agradezco a Ramón Mahía, profesor del Departamento de Economía Aplicada de la UAM, sus consejos y ayuda en los análisis estadísticos realizados.
} 
En la Tabla 6 aparecen los coeficientes de correlación y las pruebas "t" de significatividad que muestran, como cabía esperar, que sí existe correlación positiva y significativa en la relación entre las frases 1 y 2 , así como entre las frases 3 y 4 , lo que permite afirmar la existencia de sendos polos de representación, respectivamente, ilustrada y crítica. También existe una correlación, en este caso negativa, entre las frases 1 y 3 , y entre las frases 2 y 4 , pero debe destacarse que los coeficientes de correlación, aunque confiables en términos estadísticos, son bajos. Y, de otro lado, prácticamente no existe correlación negativa (o a lo sumo es muy baja), ni significativa, entre las frases 1 y 4 . Y finalmente no hay correlación entre las frases 2 y 3 , dado que aquí pueden converger las puntuaciones de ilustrados, críticos y ambivalentes. De todo ello puede concluirse que la ambivalencia tiene un papel destacado a la hora de conformar el núcleo de las representaciones sociales de la ciencia, al menos en lo que se refiere a los tres ejes considerados en la redacción de la pregunta sometida a análisis.

Tabla 6.

Coeficiente de correlación simple y prueba " $t$ " de significatividad ${ }^{3}$

\begin{tabular}{|l|c|r|r|r|r|r|r|r|}
\hline & \multicolumn{2}{|c|}{ Frase 1 } & \multicolumn{2}{c|}{ Frase 2 } & \multicolumn{2}{c|}{ Frase 3 } & \multicolumn{2}{c|}{ Frase 4 } \\
\hline Frase 1 & - & - & 0,422 & 0,00 & $-0,129$ & 0,001 & $-0,015$ & 0,694 \\
\hline Frase 2 & - & - & - & - & 0,000 & 0,996 & $-0,104$ & 0,005 \\
\hline Frase 3 & - & - & - & - & - & - & 0,275 & 0,000 \\
\hline
\end{tabular}

Finalmente, más allá de los contrastes de dependencia y de las medias de asociación, resulta también muy interesante un análisis cruzado de las frecuencias de respuestas a las distintas frases. Así, por ejemplo, un $17,1 \%$ de la muestra (excluido el NS/NC) contestó con una puntuación igual o superior a cuatro, tanto en la primera frase (prosperidad) como en la cuarta (fuente de pesadillas). Y si consideramos puntuaciones iguales o superiores a 3 en ambas frases, el porcentaje se eleva hasta el $44,7 \%$ del total. Por esta razón, perfilé una tipología a partir de las distintas variaciones posibles de puntuaciones utilizando las cuatro frase señaladas y hallé las frecuencias que registraba cada tipo (Tabla 7).

\footnotetext{
${ }^{3}$ Para cada cruce de variables se ofrece el coeficiente de correlación simple y la probabilidad del contraste asociado al valor del mismo. La probabilidad reflejada puede utilizarse para valorar la confiabilidad del coeficiente de correlación estimado.
} 
RIS

REVISTA INTERNACIONAL DE SOCIOLOGIA

El primero, al que he llamado "Ilustrados No Ambivalentes", está formado por aquellos encuestados que en las frases primera (prosperidad) y segunda (resolución de problemas) puntuaban con un 3,4 ó 5, es decir, grado medio o alto de acuerdo y, a la vez, en las frases tercera (resolución y creación de problemas) y cuarta (fuente de pesadillas) puntuaban con un 1,2 ó 3, es decir, grado medio o alto de desacuerdo.

El segundo tipo, al que he llamado "Críticos No Ambivalentes", está compuesto por quienes en las frases tercera (resolución y creación de problemas) y cuarta (fuente de pesadillas) puntuaban con un 3, 4 ó 5, es decir, grado medio o alto de acuerdo y, a la vez, en las frases primera (prosperidad) y segunda (resolución de problemas) puntuaban con un 1, 2 ó 3, es decir grado medio o alto de desacuerdo.

El tercer y último tipo, al que he llamado "Ambivalentes Manifiestos", está formado por aquellos encuestados que en las frases primera (prosperidad) y segunda (resolución de problemas) puntuaban con un 3, 4 ó 5, es decir, grado medio o alto de acuerdo y, a la vez, en las frases tercera (resolución y creación de problemas) y cuarta (fuente de pesadillas) puntuaban también con un 3, 4 ó 5 , es decir, grado medio o alto de acuerdo.

Esta clasificación tiene el inconveniente de que permite que en los tres tipos aparezcan aquellos que puntúan con un 3 las cuatro frases. En total son 11 personas, que he restado del total obtenido en cada uno de los tres tipos arriba establecidos, y que he sumado a una cuarta categoría llamada "Resto" (Posibles Ambivalentes Latentes). También he registrado el número de personas que contestaban No Sabe o No Contesta en cada una de las referidas cuatro afirmaciones. Casualmente también son otras 11 personas que, a efectos de cálculos de porcentajes, he excluido. Por supuesto que existen otras muchas combinaciones posibles, a las que podría englobarse bajo la etiqueta de "Ambivalentes Latentes". Por ejemplo, quienes optaban por puntuar con un 2. (desacuerdo) la primera frase (prosperidad), con un 4 (acuerdo) la segunda y la tercera (resolver problemas, y resolverlos y crearlos), y con un 2 (desacuerdo) la cuarta frase (fuente de pesadillas). En concreto, si consideramos las cinco puntuaciones posibles (de 1 a 5) para las cuatro frases, el número de variaciones con repetición posibles es de 625, y los tres tipos arriba perfilados suponen un total de sólo 243 ( 81 en cada uno de los tres tipos). Además, si se incluyera el No sabe y el No contesta, las variaciones con repetición posibles alcanzarían el número de 2.401 .

Pero he estimado que defender una lógica falsacionista, como he asumido en mis escritos de índole epistemológica, me debiera llevar a eliminar las ventajas que para mi tesis proporciona el amplio número de combinatorias posibles (382) de ese cuarto tipo de "Ambivalentes Latentes". Con todo, en la tabla siguiente también presento sus datos, etiquetados como "Resto" (Posibles Ambivalentes Latentes) como una referencia adicional comparativa, en la que también figuran los que señalan No Sabe o No Contesta en, como máximo, tres de las cuatro frases consideradas. 
Bajo esta misma lógica falsacionista, también pensé no tomar en cuenta en la elaboración de la tipología a los que responden con el punto medio (3), siempre más proclive a las posiciones indefinidas. Pero entonces los resultados eran todavía más favorables a la hipótesis de la ambivalencia cuando se comparaban los datos absolutos de los "Ambivalentes Manifiestos" con la de los grupos de los "Ilustrados" " "Críticos No Ambivalentes". En todo caso, y como era de prever, el mayor beneficiado de esta operación es el aumento del tipo de "Resto" (Posibles Ambivalentes Latentes), tal como aparece en la señalada Tabla 7, en consonancia con el predominio de la puntuación media de 3 y la ausencia de un perfil nítido en la mayor parte de la opinión pública.

En suma, a pesar de todas estas cautelas metodológicas, los resultados siguen siendo favorables, frente a la tesis ilustrada o crítica, a la hipótesis de la ambivalencia en las representaciones sociales concretas de la tecnociencia, tanto cuando se considera la puntuación media de 3 , como cuando se elimina este punto medio.

Sin embargo, este predominio de los juicios ambivalentes en las representaciones sociales de la tecnociencia en sus aspectos concretos, no impide que al

Tabla 7.

\begin{tabular}{lcccc}
\hline TIPOLOGÍA & $\begin{array}{c}\text { Números } \\
\text { Absolutos } \\
(1)\end{array}$ & $\begin{array}{c}\text { \% sobre } \\
\text { muestra } \\
\text { valida }\end{array}$ & $\begin{array}{c}\text { Números } \\
\text { Absolutos } \\
(2)\end{array}$ & $\begin{array}{c}\% \text { sobre } \\
\text { muestra } \\
\text { valida }\end{array}$ \\
\hline Ilustrados No Ambivalentes & 90 & $11,4 \%$ & 19 & $2,4 \%$ \\
Críticos No Ambivalentes & 106 & $13,4 \%$ & 23 & $2,9 \%$ \\
Ambivalentes Manifiestos & 267 & $33,9 \%$ & 94 & $11,9 \%$ \\
Resto (Posibles Ambivalentes Latentes) & 326 & $41,3 \%$ & 653 & $82,8 \%$ \\
NS/NC (3) & 11 & - & 11 & - \\
TOTALES & 800 & 100 (N:789) & 800 & 100 (N:789) \\
\hline
\end{tabular}

(1) Se incluyen las puntuaciones de 3 , salvo quienes contestan a las cuatro frases con dicha respuesta (once personas) que aparecen en la categoría de "Resto" (Posibles Ambivalentes Latentes).

(2) No se incluyen las puntuaciones de 3, salvo en el cuarto tipo de "Resto" (Posibles Ambivalentes Latentes).

(3) Sólo los que contestan No sabe o No contesta en las cuatro frases.

Fuente: Elaboración propia sobre datos de la encuesta sobre cultura científica de la Comunidad de Madrid (2000). 
RIS

REVISTA INTERNACIONAL DE SOCIOLOCIA

No 42, SEPTIEMBRE-DICIEMBRE, 2005

CRISTÓBAL TORRES ALBERO

plantear a los entrevistados una disyuntiva explícita sobre la ciencia en términos generales - la segunda pregunta antes enunciada - los datos de las respuestas muestren (Tabla 8) para la Comunidad de Madrid un significativo predominio de

Tabla 8.

Pregunta: Si tuviera usted que hacer balance de los aspectos positivos y negativos de la ciencia, ¿cual de las siguientes opciones que le presento en la siguiente tarjeta reflejaría mejor su opinión?

\begin{tabular}{|l|c|c|c|c|}
\hline \multicolumn{1}{|c|}{ OPCIONES } & $\begin{array}{c}\text { Encuesta } \\
\text { CAM 2000 } \\
(1)\end{array}$ & $\begin{array}{c}\text { Encuesta } \\
\text { FECYT 2002 } \\
(2)\end{array}$ & $\begin{array}{c}\text { Encuesta } \\
\text { CAM 2004 } \\
(3)\end{array}$ & $\begin{array}{c}\text { Encuesta } \\
\text { FECYT 2004 } \\
(4)\end{array}$ \\
\hline $\begin{array}{l}\text { Teniendo en cuenta } \\
\text { todos los aspectos, los } \\
\text { beneficios de la ciencia } \\
\text { son mayores que sus } \\
\text { perjuicios }\end{array}$ & $58,3 \%$ & $46,7 \%$ & $58,5 \%$ & $46,9 \%$ \\
\hline $\begin{array}{l}\text { Teniendo en cuenta } \\
\text { todos los aspectos, los } \\
\text { perjuicios de la ciencia } \\
\text { son mayores que los } \\
\text { beneficios }\end{array}$ & $6,5 \%$ & $9,9 \%$ & $4,5 \%$ & $12,1 \%$ \\
\hline $\begin{array}{l}\text { Teniendo en cuenta } \\
\text { todos los aspectos, los } \\
\text { beneficios y perjuicios } \\
\text { de la ciencia están } \\
\text { equilibrados. }\end{array}$ & $24,4 \%$ & $32,2 \%$ & $30,7 \%$ & $33,4 \%$ \\
\hline $\begin{array}{l}\text { No tengo una opinión } \\
\text { formada sobre este } \\
\text { aspecto. }\end{array}$ & $10,1 \%$ & $9,3 \%$ & $4,3 \%$ & $7,1 \%$ \\
\hline No contesta & $0,7 \%$ & $1,9 \%$ & $2,0 \%$ & $5,0 \%$ \\
\hline TOTAL & 100 & 100 & 100 & 100 \\
\hline
\end{tabular}

(1) Encuesta sobre cultura científica de la Comunidad de Madrid (2000). 800 entrevistas en la CAM a personas de 18 y más años.

(2) Encuesta FECYT sobre percepción social de la ciencia y la tecnología en España (2002). 2.448 entrevistas en el conjunto de España a personas de 15 y más años.

(3) Encuesta sobre cultura científica y tecnológica (BSO2001-0171/CPSO) financiada por el Ministerio de Ciencia y Tecnología. 1.000 entrevistas en la CAM a personas de 18 y más años.

(4) Encuesta FECYT sobre percepción social de la ciencia y la tecnología en España (2004). 3.400 entrevistas en el conjunto de España a personas de 15 y más años.

Fuente: Elaboración propia. 
la valoración meliorativa de la ciencia (58\%), y un peso de la opción ambivalente en su variante explícita $(24,4 \%)$ que es significativo pero que es notablemente inferior al registrado para la idea positiva, inclusive si sumamos a esta última opción a aquellos que declaran que no tienen una opinión formada sobre la relación entre beneficios y perjuicios $(10,1 \%)$, y a quienes suscriben la posición crítica $(6,5 \%)$.

No obstante, como se aprecia en la citada tabla, los datos más recientes de otra encuesta realizada a finales de 2004 en la Comunidad de Madrid (y todavía en proceso de depuración y explotación) muestran un crecimiento de seis puntos de las opiniones ambivalentes $(30,7 \%)$, si bien tal incremento resulta a costa del descenso de quienes no tienen una opinión formada y de los críticos. Este dato de la opción ambivalente es parejo al aportado por dos encuestas de la FECYT dedicadas a la "percepción social de la ciencia y la tecnología en España", con el trabajo de campo realizado también por Demoscopia en los últimos cuatrimestres de 2002 y 2004 (32,2\% y 33,4\%, respectivamente). Ambas encuestas usaron la misma pregunta que inicialmente diseñé para la encuesta de la Comunidad de Madrid de 2000, si bien su ámbito fue nacional y el universo incluía a la población de 15 y más años. No obstante, la encuesta de la FECYT de 2004 no sólo incluía en la redacción de la pregunta la referencia a la ciencia, sino que la ampliaba a la ciencia y la tecnología.

Es decir, a pesar de que la cuantificación de la ambivalencia en la representación social de la tecnociencia no es similar cuando se plantea en términos generales o en sus ejes más concretos, ni cuando se establece una disyuntiva explícita o se permiten expresar las opiniones en un abanico más amplio de posibilidades, los datos de las diversas encuestas disponibles sugieren un ligero pero sostenido aumento en los últimos años del número de posiciones ambivalentes, también cuando se plantea la cuestión como disyuntiva y en términos generales. Con todo, esta última afirmación requiere profundizar y ampliar la evidencia comparativa de índole cuantitativa.

\section{LA FUENTE DE LA AMBIVALENCIA ANTE LA TECNOCIENCIA}

Con independencia de la evidencia empírica aportada en los epígrafes anteriores, y de su diferente concreción según el nivel latente o manifiesto de análisis y el contexto social considerado, cabe identificar la base estructural que posibilita una representación social ambivalente de la ciencia y la tecnología en la dualidad - intrínseca a su naturaleza - entre, por un lado, la (positiva) posibilidad de constante innovación que se traduce en progreso, abundancia y mejora de la calidad de vida y, por otro, la (negativa) permanente posibilidad de alterar los supuestos de la vida natural, que alcanza sus extremos en la alteración de los ciclos básicos de la naturaleza y en la posible ausencia de orientaciones éticas con las que hacer frente a las realidades 
RIS

REVISTA INTERNACIONAL DE SOCIOLOGÍ

$\mathrm{N}^{\circ}$ 42, SEPTIEMBRE-DICIEMBRE, 2005

CRISTÓBAL TORRES ALBERO

artificiales que la tecnociencia ha hecho posible. Por ello, en ocasiones las actitudes ante la misma son de apoyo y entusiasmo, y en otros casos la respuesta es la desconfianza, cuando no el enojo y el rechazo. En esta disyuntiva radica, a mi entender, la fuente de la permanente ambivalencia ante la tecnociencia, con independencia de su mayor o menor presencia en determinados contextos y momentos, y de que en cada dinámica histórica concreta las representaciones sociales de la ciencia y la tecnología pueda encauzarse en un mayoritario sentido meliorativo o peyorativo.

Handlin (1980), el primero en sostener académicamente la tesis de la ambivalencia como forma de respuesta popular ante la ciencia y la tecnología, refirió que esta tensión dual ha existido en el pasado, vive en el presente y, seguramente, persista en el futuro, dado que los individuos se sienten simultáneamente complacidos por los años adicionales de esperanza de vida y aterrorizados por la bomba atómica. Argumenta este autor que siempre hubo una aquiescencia a regañadientes en las representaciones sociales de la ciencia y la tecnología, y los continuos sobresaltos en las innovaciones técnicas acabaron por romper el débil equilibro conseguido en un inicio. En las primeras máquinas del siglo XVIII no hubo ningún corte brusco en la continuidad de los procesos de producción. Así, tanto en los primeros usos de las nuevas técnicas, como en el trabajo en las primeras fábricas, existía una familiaridad con lo ya conocido y también una promesa de mejora de la vida. Sin embargo, conforme las nuevas invenciones desplazaban a los artesanos y las formas tecnológicas se hicieron incomprensibles para los trabajadores, el inicial optimismo se trocaba, de cuando en cuando, en resentimiento y hostilidad.

En esta perspectiva debemos situar el movimiento luddita, que llevó a que en la primera década del siglo XIX una parte de los trabajadores de la industria textil británica se movilizaran contra la introducción de los nuevos telares a vapor, desencadenando una oleada de agitación social y destrucción de máquinas que tomó el nombre de la mítica figura de Ned Ludd (Manuel, 2002). El luddismo adquirió especial relevancia como primera expresión del cuestionamiento y rechazo de la tecnología en la emergente sociedad moderna, de la misma manera que el libro de Mary Shelley, Frankenstein o el moderno Prometeo (1818), constituye la primera visión sombría de la ciencia. Aunque no fueron los primeros, el libro de Shelley, junto con El Extraño caso de Dr. Jekyll y Mr. Hyde (1886) de Robert Louis Stevenson, son los dos grandes hitos de las primeras críticas a la ciencia y al papel de los científicos como modernos prometeos al servicio del bienestar de la humanidad.

Cuando Mary Shelley publicó su Frankenstein, el galvanismo implicaba la liberación de misteriosas fuerzas vitales por medio de la electricidad. Las preguntas más repetidas sobre el galvanismo eran si se podría llegar a producir la vida a partir de los tejidos muertos. Sobre esta base, y en contraposición del espíritu romántico con el ideal ilustrado, Shelley da cuenta de que la fuerza de la ciencia reposa en el desafio a cualquier autoridad. La trasgresión del orden natural y la creación de una criatura artificial es un acto con el que la ciencia niega las leyes de la naturaleza. 
Con esto, la autora presenta una imagen del científico como decidido a obtener conocimiento oculto y potencialmente peligroso. Víctor Frankenstein está tan obsesionado con su proyecto de investigación que no duda en poner en peligro su círculo social con tal de llegar al final para conocer su habilidad para comprender y controlar la naturaleza. Y así, aun cuando el galvanismo ya no es una teoría en uso, el mito de Frankenstein ha cobrado en nuestros tiempos una renovada centralidad, dadas las potencialidades de alteración de los patrones básicos de la naturaleza biológica que suponen los desarrollos actuales de la biotecnología y la manipulación genética (Ordóñez, 2004).

El libro de Louis Stevenson, Dr. Jekyll y Mr. Hyde, constituye otra obra de referencia básica que aborda la potencial amenaza que para los más básicos valores de la vida y la sociedad provoca la ciencia. En este libro Stevenson pone de manifiesto cómo la ciencia puede llegar a conseguir que el ser humano sea más de uno al mismo tiempo, jugando a separar nuestros componentes y dejando a la ciencia sin responsabilidades. El doctor que reparte su tiempo de científico con sus reuniones de sociedad, da rienda suelta a Hyde que, escapándose por la puerta trasera del callejón sombrío, representa la crueldad y la malicia.

De esta manera ambas novelas hicieron explícito en el imaginario popular los temores de la población respecto a la tecnociencia. Handlin (1980: 254) lo ha recordado retomando un pasaje del libro de Shelley y las palabras que la criatura dirige a su creador: "Esclavo, antes yo razonaba contigo, pero has demostrado ser indigno de mi condescendencia. Recuerda que tengo poder....Puedo hacerte tan desdichado que la luz del día sería diosa para ti. Tú eres mi creador, pero yo soy tu amo. ¡Obedece!". De esta manera, aunque no hubo maldad en el comienzo de la investigación del Dr. Frankenstein y en su uso de la ciencia y la tecnología, el resultado fue que la nueva criatura acabó convirtiéndose en el patrón opresivo del hombre (Ordóñez, 2004).

Esta misma línea es la que posteriormente siguen las llamadas distopías. Así, frente a las tradicionales utopías del siglo XIX destinadas al bosquejo de las sociedades ideales, del tipo socialismo utópico de los falansterios, o la aplicación del método científico a la organización de la sociedad, ya desde finales del XIX y primeros del XX cobran especial relevancia literaria las distopías o descripción de cómo las consecuencias del progreso científico y la modernización pueden afectar a las fronteras de la libertad, provocando la configuración de una organización social que, en consonancia con regímenes políticos totalitarios, destruye los más básicos principios de la libertad humana. Autores y obras como Huxley, Un mundo feliz (1932), Skinner, Walden dos (1948), u Orwell con 1984 (1949), tienen como eje común la tesis de que la ciencia y la tecnología producen, o se convierten en legitimadores de, sistemas políticos autocráticos.

En suma, un sutil presagio de las consecuencias de la ciencia y la tecnología inquietaba ya a los individuos más susceptibles de creer en el carácter beneficioso de la ciencia. Y en los intentos de concebir el futuro se hacía explícito en el ima- 
RIS

REVISTA INTERNACIONAL DE SOCIOLOGIA

№ 42, SEPTIEMBRE-DICIEMBRE, 2005

CRISTÓBAL TORRES ALBERO

ginario popular el temor que inquietaba a la población: que la nueva criatura (la ciencia) a través del moderno Prometeo (el científico) se acabara convirtiendo en el patrón opresivo del hombre y de la sociedad, a los que acabase por destruir moral y materialmente.

Pero, aun con estos destacables episodios de contestación material e intelectual, el proceso general y mayoritario que vivieron las emergentes sociedades capitalistas del siglo XIX y principios del XX fue de un acentuado optimismo confiado en las posibilidades de la ciencia y la tecnología, especialmente en el caso de Estados Unidos (Smith, 1996). Sin duda, el hecho de que los actores sociales protagonistas fueran, básicamente, élites interesadas bien en la industrialización y el progreso económico, bien en usar la razón y el conocimiento para cambiar con estas ilustradas armas las estructuras tradicionales de ignorancia y superstición, tuvieron que ver con esta hegemonía. Preeminencia que se reforzaba porque la ciencia y la tecnología no sólo prometían cosas, sino que también deslumbraban al más amplio público con sus hallazgos y sus artefactos concretos.

Sin embargo, la ciencia y la tecnología nunca conquistaron por completo las simpatías ciudadanas. No sólo porque persistían las creencias tradicionales populares, sino también porque estas fuerzas comenzaron a hacerse incomprensibles para la inmensa mayoría de la sociedad, que carecía de unos niveles básicos de instrucción educativa o de alfabetización tecnocientífica. Algo que no sólo ocurría en la ciencia y en las nuevas respuestas que proporcionaba, por poner dos ejemplos, sobre el cielo (Einstein y la teoría de la relatividad) o la moral de las personas (Freud y el psicoanálisis), sino también sobre la tecnología presente en las fábricas. Así, frente a la energía hidráulica o el vapor que podían comprenderse directamente, Handlin (1980: 257) destaca que "en las fabricas construidas en 1900 los engranajes y las poleas ya no eran visibles. La energía se transmitía por cables y tubos (a menudo ocultos), y todo se hallaba cubierto y protegido de modo que la máquina diese la apariencia de ser autosuficiente y autónoma. El espectador ya no veía un aparato comprensible, sino una estructura cerrada operada por una fuente oculta de energía y de la cual salían determinados productos gracias a un proceso oculto. Si eran pocos los que podían entender cómo una corriente eléctrica que pasa por un cable puede originar luz y sonido o hacer girar las ruedas de grandes máquinas, menos eran aún los que comprendían los procesos involucrados en la aplicación tecnológica de conocimientos provenientes de la electroquímica o de la física nuclear moderna a los instrumentos con los que trabajaban".

De otro lado, los científicos y tecnólogos se distanciaron definitivamente de la más amplia sociedad con la configuración de sus propias comunidades al hilo de los procesos de institucionalización, profesionalización y especialización, con lo que se acabó produciendo un profundo alejamiento entre los saberes y creencias populares y la profesión de los científicos y tecnólogos. 


\section{ELDESENCADENANTE DE LAAMBIVALENCIA EN LAS SOCIEDADES CONTEMPORÁNEAS}

Pero si el sentimiento de distancia y de consideración de los peligros asociados a la ciencia y la tecnología se mantuvo en el primer tercio del siglo XX (como expresan las distopías ya citadas), éste coexistía con una corriente de simpatía y confianza en sus actividades y resultados que se acrecentó a la raíz del papel que la tecnociencia jugó en la victoria aliada en la Segunda Guerra Mundial. Al finalizar ésta se conformó un ambiente de apoyo y confianza mayoritario que pasaba por concederle un papel central en la reconstrucción material y reorganización social de las destruidas sociedades occidentales. Etzioni y Nunn (1974) dan cuenta de las positivas actitudes ante la ciencia de la sociedad norteamericana en la década de los cincuenta. Con todo, también registran el descenso de dicha meliorativa apreciación, y el significativo aumento de las opiniones de reserva a lo largo de la década de los sesenta y principios de los setenta.

En efecto, pronto la carrera armamentística nuclear que desencadenó la Guerra Fría, asociada al recuerdo de muerte y destrucción de Hiroshima y Nagasaki, la creciente constatación de los riesgos potenciales y peligros reales de los residuos tóxicos químicos y nucleares, las distintas manifestaciones del visible y continuo deterioro del medio ambiente, la posibilidad real de alterar los ciclos básicos de la naturaleza, la aceleración del proceso de disolución de los saberes y experiencias tradicionales, la creciente deshumanización y alienación en los puestos de trabajo por razón de la tecnificación de la cadena productiva y, en suma, la asunción de unas pautas de producción y consumo que cambiaron los valores morales por las necesidades y los estilos de vida naturales por sofisticadas formas artificiales, supusieron el definitivo espaldarazo para que, a partir del momento simbólico del Mayo del 68, comenzara a producirse una progresiva erosión en la confianza de la sociedad en la tecnociencia y la consiguiente activación de posiciones críticas. Este proceso, en ocasiones liderado por los propios científicos (como el grupo Science for the people), puso en entredicho la positiva y plácida imagen de los efectos del desarrollo científico y tecnológico, y devino en la ruptura de lo que Blanco e Iranzo (2000) han llamado el contrato social implicito a favor de la ciencia.

El proceso de quiebra se acrecentó tanto por el papel agitador que jugaron plataformas críticas ligadas a la izquierda intelectual, como por la constatación de que no se podía mantener por más tiempo la creencia de que existía una separación entre la ciencia como positivo avance del conocimiento y del bienestar, y la tecnología como negativa posibilidad de generar situaciones de riesgo o peligro. Esta es la línea que mantendrán y enriquecerán autores como Habermas, Marcuse o Feyerabend en su crítica al cientifismo y a la tecnocracia. La crítica fundamental de Habermas (1992) estableció que, en nombre de una pretendida neutralidad técnica, se ha preconizado la disolución o arrinconamiento de aquellos valores 
sociales cuyas posibilidades de plasmación escapaban a las posibilidades técnicas concretas de cada momento. De esta manera, la pluralidad de los valores sociales se reduce a un mero reflejo del estadio de desarrollo científico-técnico, se disuelven los restantes y se adopta una imagen de pretendida neutralidad que, en realidad, esconde las claves de una determinada forma de organizar, entender y valorar las relaciones sociales de dependencia y explotación establecidas. Algo que ha permitido el surgimiento de lo que Marcuse (1993) denominó el hombre unidimensional, es decir, aquel que ha abandonado cualquier otro valor o componente distinto a aquellos que se derivan del ámbito consumista y tecnocientífico. No es de extrañar, por tanto, que Feyerabend (1986) haya afirmado que la ciencia y la tecnología, lejos de ser una actividad neutral u objetiva, se ha erigido en un mecanismo ideológico que, al modo de la religión en las sociedades preindustriales, permite la hegemonía de un determinado tipo de conocimiento frente al resto de tradiciones. Esta corriente afirma que la promesa de liberación humana que incorporaba la ciencia y la tecnología a lo largo de los siglos anteriores se vio truncada una vez que ésta asentó sus vínculos con los grupos sociales que controlaban el Estado. De esta convergencia han surgido grupos como los técnicos o especialistas, que se encargan de velar para que la ciencia, alejada de su idealizada imagen, sirva a los intereses del capital y del Estado dentro de unas relaciones de producción capitalistas, sean de índole privada o de carácter estatal.

Así pues, el deterioro de la confianza, el crecimiento del discurso crítico, y la notable visibilidad y aumento de los juicios ambivalentes sobre la tecnociencia, se deben a que la estructura de las actuales sociedades avanzadas ha activado plenamente la ya reseñada fuente dual que la tecnociencia presentaba desde su irrupción histórica. Activación que se debe al papel central, e incluso hegemónico, que ésta juega en las sociedades avanzadas. En este sentido, Lamo de Espinosa (1996) ha calificado a nuestras sociedades como sociedades de conocimiento y de ciencia en tanto que la tecnociencia es la principal fuente de riqueza, el factor productivo principal, la ocupación mayoritaria, el problema político central y el modo dominante de pensamiento.

Este panorama se ha hecho más nítido en la última década del siglo XX, dado que la tecnociencia no sólo ha consolidado su estratégico papel en la articulación productiva, sino que también, al hilo de la actual revolución de las tecnologías de la información y las comunicaciones, así como de la acaecida en el campo de la biotecnología o ingeniería genética, se ha intensificado la demanda de la aplicabilidad de sus productos cognitivos y técnicos, a la par que agentes sociales de distinta índole (ecologistas, consumidores, etc.) exigen, cada vez en mayor número y con mayor intensidad, que se controlen y atemperen, cuando no que se eliminen, los efectos no deseados que su actividad produce en la estructura social y en el medio ambiente. Esta es una de las ideas expresadas por Beck (1998) cuando indica que la sociedad del riesgo, como etapa final del proceso de 
modernización, tiene que ver con la dualidad de una sociedad que demanda a la tecnociencia el mantenimiento, cuando no el aumento, del progreso y la riqueza económica y social, a la vez que identifica las negativas consecuencias que para la sociedad como un todo global, el medio ambiente y el futuro de las generaciones más jóvenes comporta tal exigencia. El resultado, dada la posibilidad real de catástrofe ecológica, es la idea de sociedad del riesgo como forma de caracterizar a las sociedades avanzadas. Y por ello, Bauman (2005) ha ligado la emergencia de la ambivalencia, junto con los sentimientos de inseguridad e incertidumbre, a los riesgos de la modernización.

Dada la reseñada centralidad de la tecnociencia, el siempre difícil equilibrio entre los pros y los contras de las consecuencias prácticas de la ciencia y la tecnología se vuelve más complicado y frágil. Así, junto al papel de la tecnociencia en el desarrollo económico y la mejora del bienestar de las personas y las sociedades, es innegable que, aparte de los aspectos negativos ya reseñados al inicio de este epígrafe, ésta también genera nuevos procesos, imprevisibles hasta hace unos años, como la creación de nuevas formas de desigualdad social que se conocen con el apelativo de la brecha digital (en las personas de más edad, con un nivel bajo de estudios u ocupadas en trabajos menos afectados por los cambios tecnológicos, que se convierten en nuevos analfabetos digitales), y que no solo afectan a personas o grupos sociales concretos, sino también a países y a regiones geopolíticas específicas, dado que la barrera entre norte y sur es, además de económica, cultural o, en clave de nuestra argumentación, tecnocientífica.

En definitiva, la centralidad de la tecnociencia en las sociedades desarrolladas, con lo que en la experiencia cotidiana implican sus ventajas e inconvenientes, ha acabado disparando la ambivalencia y las críticas hacia ella, con la consecuente disminución de las posiciones meliorativas, al producirse dos tipos de situaciones históricamente desconocidas. De un lado, las ya mencionadas posibilidades de alterar los ciclos básicos de la naturaleza y el riesgo de catástrofe ecológica que se deduce de ello. Sentimiento reforzado por casos como el accidente de Chernobil o la crisis de las llamadas "vacas locas", que se entienden como avisos o indicios de algo más serio que, de manera verosímil, puede ocurrir en un futuro próximo. Como se indicaba en las reuniones de grupo, puede discutirse si la tecnociencia es responsable de estas situaciones, pero existe acuerdo en que las ha hecho posible. De otro lado, su continua rutina de innovación ha acabado generando novedades y situaciones para las que se carece de orientaciones éticas, como, por ejemplo, el actual desarrollo de la biotecnología. La tecnociencia obedece a la razón instrumental y, por tanto, es incapaz de decir nada sobre los fines que ha logrado, aunque los haya creado a partir de determinados medios, e incluso con esos mismos medios haya disuelto buena parte de la razón moral tradicional. 
RIS

REVISTA INTERNACIONAL DE SOCIOLOCIA

№ 42, SEPTIEMBRE-DICIEMBRE, 2005

CRISTÓBAL TORRES ALBERO

\section{CONCLUSIONES}

Sobre la tesis de la ambivalencia en las representaciones sociales de la tecnociencia hay que precisar que ésta no es sinónimo de inconsistencia, ni implica necesariamente una contradicción en las opiniones. Noya (2004), que ha realizado un detallado recorrido sobre los distintos autores que han tratado la cuestión de la ambivalencia, ha destacado la ilusión que se crea en torno a la idea de consistencia y la ha ilustrado destacando el bajo número de situaciones en las que el conjunto de opiniones son consistentes. Así, conforme los procesos sociales se convierten en complejos y abstractos, la consistencia de los distintos conceptos tiende a difuminarse, se estiran o se contraen, y la lógica de la congruencia se convierte en inoperante. Y, con ello, la ambivalencia no sólo alcanza a aquellos que mantienen una actitud dual explícita, sino también a quienes presentan actitudes poco definidas, carecen de las mismas, no saben que pensar por falta de información, etc.

De esta manera, la ambivalencia se convierte en una forma eficiente de neutralización de la complejidad, permitiendo que valores e ideas etiquetadas como incompatibles cohabiten sin tensión y que, en función de la connotación de cada momento y contexto social, puedan prevalecer alternativamente. Salvo aquellos actores con creencias y valores sólidos y arraigados, el resto sólo otorgan un valor determinado al objeto ante un problema preciso y en una situación histórica concreta. Con ello cabe establecer que los actores sociales acaban generando repertorios variados, e incluso opuestos entre sí, de creencias para referirse a un mismo objeto, puesto que ello les permite una capacidad activa de discriminación y juicio ante distintos problemas y situaciones.

Por tanto, y asumiendo en este punto la conceptualización que hizo Moscovici (1984) remozando la tradicional tesis de Durkheim (1898) de las representaciones colectivas, sostengo que el núcleo figurativo que conforma el campo de las representación social de la tecnociencia está construido a partir de la fuente dual de la tecnociencia que arriba hemos identificado y que posibilita una esquematización estructurante de elementos e imágenes figurativas ambivalentes para sustituir a las dimensiones conceptuales más complejas y abstractas que implican la ciencia y la tecnología. Ambivalencia que en ocasiones se activa por completo, pero que en otros momentos permite la hegemonía bien del polo positivo, bien del negativo, en función de los rasgos concretos de la estructura social en la que se inserta en la tecnociencia en un tiempo histórico determinado, y de las dinámicas de interacción entre los agentes sociales involucrados en esta materia y la más amplia opinión pública (Torres, 2005).

En suma, puede concluirse que en las sociedades avanzadas occidentales la tecnociencia ha conseguido un alto nivel de penetración en sus diversos ámbitos $\mathrm{y}$, con ello, ha conformado un crucial vector que es sometido a una evaluación crítica continua por un público que espera obtener continuos beneficios, a la vez 
que cada vez está más alerta sobre la posibilidad de encontrar, en sus numerosas y variadas actividades, problemas y perjuicios en aspectos determinados y casos concretos. El resultado final es la activación, cada vez en mayor medida, de un discurso explícito ambivalente en las sociedades contemporáneas ante la ciencia y la tecnología.

\section{REFERENCIAS BIBLIOGRÁFICAS}

ATIENZA, J. y J.L. LUJÁN (1997), La imagen social de las nuevas tecnologias biológicas, Madrid, CIS. Colección Opiniones y Actitudes n 14.

BAUMAN, Z. (2005), Modernidad y ambivalencia, Barcelona, Anthropos.

BECK, U. (1998), La sociedad del riesgo, Barcelona, Paidós.

BLANCO, J. R. y J. M. IRANZO (2000), "Ambivalencia e incertidumbre en las relaciones entre ciencia y sociedad", Papers n ${ }^{\circ}$ 61, pp. 89-112.

COMTE, A. (1995), Discurso sobre el espiritu positivo, Madrid, Altaya.

DÍAZ DE RADA, V., P. AYERDI y M. OLAZARAN (1998), "Percepción social de la ciencia y la tecnologia en España", RIS, n 21 , pp. 73-100.

DURKHEIM, E. (1898), "Représentations individuelles et représentations collectives", Revue de Métaphysique et de Morales, tomo VI (mai), pp. 273-300. (También reproducido en E. Durkheim, Sociología y filosofia, Madrid, Miño y Dávila editores, 2000).

(1982), Las formas elementales de la vida religiosa, Madrid, Akal.

ETZIONI, A. y C. NUNN (1974), "The public appreciation of science in contemporary America", Daedalus, vol. 3, 3, pp. 195-205.

FECYT (2003 y 2005), Percepción social de la ciencia y la tecnologia en España, Madrid, FECYT.

FEYERABEND, P. (1986), Tratado contra el método, Madrid, Tecnos.

GONZÁLEZ BLASCO, P. (1993), "Actitudes sociales ante la ciencia y la tecnología”, $R I S \mathrm{n}^{\circ} 4$, pp. 233-270.

HABERMAS, J. (1992), Ciencia y tecnologia como ideologia, Madrid, Tecnos.

HANDLIN, O. (1980), "La ambivalencia en la reacción popular ante la ciencia", en B. Barnes et al., Estudios sobre sociologia de la ciencia, Madrid, Alianza Editorial, pp. 247-261 (e.o. del artículo de Handlin, 1965).

HUXLEY, A. (1969), Un mundo feliz, Barcelona, Plaza \& Janés. 
LAMO DE ESPINOSA, E. (1996), Sociedades de cultura, sociedades de ciencia, Oviedo, Nóbel.

MANUEL, F.E. y otros (2002), Máquina maldita. Contribuciones para una historia del luddismo, Barcelona, Alikornio Ediciones.

MARCUSE, H. (1993), El hombre unidimensional. Barcelona, Planeta-Agostini.

MARX, K. (1978), Contribución a la crítica de la economia politica, Madrid, Alberto Corazón.

MERTON, R.K. (1980), La ambivalencia sociológica y otros ensayos. Madrid, Espasa-Calpe.

MILLER J.D., R. PARDO y F. NIWA (1998), Percepciones del público ante la ciencia y la tecnología. Estudio comparativo de la Unión Europea, Estados Unidos, Japón y Canadá. Madrid, Fundación BBV.

MOSCOVICI, S. (1984), "The phenomenon of social representations", en F. Farr y S. Moscovici (eds), Social representations, Cambridge, Cambridge University Press, pp. 3-69.

NAGEL, E. (1974), La estructura de la ciencia, Buenos Aires, Paidós.

NOYA, J. (2004), Ciudadanos ambivalentes. Actitudes ante la igualdad y el Estado del Bienestar en España, Madrid, CIS.

ORDÓÑEZ, J. (2004), La imagen de la ciencia en los relatos de ficción, Madrid, Inédito.

ORWELL, G. (1986), 1984, Barcelona, Círculo de Lectores.

PARDO, R. (2001), "La cultura científico-tecnológica de las sociedades de modernidad tardía", en $\mathrm{M}^{\mathrm{a}}$ Ángeles Durán et al., Estructura y cambio social. Libro homenaje a Salustiano del Campo, Madrid, CIS, pp. 1077-1108.

SAINT-SIMON, H. (1975), El sistema industrial, Madrid, Revista de Trabajo.

SHELLEY, M. (1999), Frankenstein o el moderno Prometeo, Madrid, Unidad Editorial.

SKINNER, B.F. (1984), Walden Dos, Barcelona, Martínez Roca.

SMITH, M.R. (1996), "El determinismo tecnológico en la cultura de Estados Unidos", en M.R. Smith y L. Marx (eds), Historia y determinismo tecnológico, Madrid, Alianza Editorial, pp. 1-36

STEVENSON, R.L. (1984), El Dr. Jekyll y Mr. Hyde, Madrid, Alianza Editorial.

TORRES, C. (2005), "Representaciones sociales de la ciencia y la tecnología", REIS (en prensa).

WEBER, M. (1971), Economia y sociedad, México, FCE. 